\title{
Thrombosis of the Vein of Galen: Pitfalls, Metamorphosis, and Paroxysmal Sympathetic Hyperactivity
}

\author{
Paulo César Santos-Soares $^{a} \quad$ Jamary Oliveira-Filho ${ }^{b}$ \\ ${ }^{a}$ Intensive Care Unit, Hospital da Cidade, Salvador, Brazil; ${ }^{b}$ Neurology Service and \\ Neurocritical Care Unit, Hospital Santa Isabel, Salvador, Brazil
}

\section{Keywords}

Cerebral venous thrombosis - Autonomic storm · Vein of Galen

\begin{abstract}
Isolated thrombosis of the vein of Galen is a rare and serious entity with few cases reported in the literature. We report the case of a previously healthy 18 -year-old male who was admitted after developing headache and subsequently worsening mental status, requiring endotracheal intubation for airway protection. During his admission he developed symptoms of severe paroxysmal sympathetic hyperactivity and posturing. The computed tomography and magnetic resonance imaging of the brain showed bilateral thalamic lesions. The magnetic resonance angiography and digital arteriography revealed a thrombosis of the deep cerebral venous system (vein of Galen). We call attention to a case with rapid symptom progression and specific radiological findings, with atypical clinical course, characterized by paroxysmal sympathetic hyperactivity, but with good clinical functional outcome.
\end{abstract}




\section{Case Reports in Neurology}

\section{Introduction}

Cerebral venous thrombosis (CVT) is a rare disorder accounting for less than $1 \%$ of stroke cases [1]. With variable clinical presentation, diagnosis should be considered in young patients who develop cerebrovascular events without traditional risk factors and in unusual arterial territories [2].

\section{Case Report}

An 18-year-old patient arrived to the hospital with headache and worsening mental status. The head computed tomography (CT) demonstrated a hypodense bilateral thalamic lesion with edema and heterogeneous contrast enhancement, associated with hydrocephalus. Cerebral spinal fluid study showed an opening pressure of $20 \mathrm{~mm} \mathrm{Hg}$. Brain magnetic resonance imaging (MRI) identified bilateral thalamic hemorrhagic infarction (Fig. 1, Fig. 2). The magnetic resonance angiography suggested CVT and the digital arteriography confirmed the presence of cerebral thrombosis of the vein of Galen (Fig. 3, Fig. 4). He underwent external ventricular drainage and was started on anticoagulation therapy. He developed paroxysmal episodes of tremors associated with sweating, fever, and tachycardia, with bilateral decerebrate posturing. After starting treatment with beta-blocker and bromocriptine, his autonomic events and level of consciousness improved. He was discharged from the ICU with mild cognitive deficit. Blood tests for major coagulopathies were uninformative.

\section{Discussion}

CVT is a serious entity. A multicenter study of 624 adult patients with CVT estimated a mortality of $3.4 \%$ in 30 days [3]. Thrombosis of the deep system represents about 3-8\% cases of CVT. As venous drainage occurs via the thalamic vessels that drain into the deep venous system, the involvement of these vessels should be considered in bilateral thalamic infarcts $[4,5]$. The severity of the condition depends on the extent of thrombosis and the presence of collateral veins [4]. Partial syndromes can occur, which can make the diagnosis challenging $[4,6]$.

Van den Bergh et al. [4] published a series of 4 cases with partial syndromes with good clinical results. Case reports with bilateral thalamic ischemia have shown variable neurological outcome [7, 8]. Crawford et al. [6] retrospectively described 7 cases of thrombosis of the deep system with 5 deaths. Isolated thrombosis of the vein of Galen is rare, with few cases reported in the literature.

Paroxysmal sympathetic hyperactivity has been mainly reported after traumatic brain injury. Pathophysiology is debated but probably results from dysfunction of sympathetic centers in the diencephalon [9]. Treatment choice is based in case series and involves bromocriptine, morphine, baclophen, and other agents with variable response [10]. After traumatic brain injury, paroxysmal sympathetic hyperactivity is not necessarily an ominous sign, with cases with full recovery reported. In our patient, response to bromocriptine was good and functional independence was achieved. 


\section{Statement of Ethics}

The authors have no ethical conflicts to disclose.

\section{Disclosure Statement}

The authors state that they have no conflicts of interest.

\section{References}

1 Einhäupl K, Stam J, Bousser MG, De Bruijn SF, Ferro JM, Martinelli I, Masuhr F: EFNS guideline on the treatment of cerebral venous and sinus thrombosis in adult patients. Eur J Neurol 2010;17:1229-1235 Stam J: Thrombosis of the cerebral veins and sinuses. N Engl J Med 2005;352:1791-1798.

- 3 Ferro JM, Canhão P, Stam J, Bousser MG, Barinagarrementeria F; ISCVT Investigators: Prognosis of cerebral vein and dural sinus thrombosis: results of the International Study on Cerebral Vein and Dural Sinus Thrombosis (ISCVT). Stroke 2004;35:664-670.

-4 Van den Bergh WM, van der Schaaf I, van Gijn J: The spectrum of presentations of venous infarction caused by deep cerebral vein thrombosis. Neurology 2005;65:192-196.

-5 Gossner J, Larsen J, Knauth M: Bilateral thalamic infarction - a rare manifestation of dural venous sinus thrombosis. Clin Imaging 2010;34:134-137.

6 Crawford SC, Digre KB, Palmer CA, Bell DA, Osborn AG: Thrombosis of the deep venous drainage of the brain in adults. Analysis of seven cases with review of the literature. Arch Neurol 1995;52:1101-1108.

-7 Hoitsma E, Wilmink JT, Lodder J: Bilateral thalamic infarction may result from venous rather than arterial obstruction. J Stroke Cerebrovasc Dis 2002;11:47-50.

-8 Marques MC, Pires LA, Damasceno CA, Felício AC, Atala A, Franco GM: Galen vein thrombosis: case report (in Portuguese). Arq Neuropsiquiatr 2003;61:285-287.

$\$ 9$ Meyer KS: Understanding paroxysmal sympathetic hyperactivity after traumatic brain injury. Surg Neurol Int 2014;5(suppl 13):S490-S492.

10 Rabinstein AA, Benarroch EE: Curr Treat Options Neurol 2008;10:151-157. 


\section{Case Reports in Neurology}

\begin{tabular}{l|l}
\hline Case Rep Neurol 2017;9:168-172 \\
\hline DOI: 10.1159/000447119 & $\begin{array}{l}\text { @ 2016 The Author(s). Published by S. Karger AG, Basel } \\
\text { www.karger.com/crn }\end{array}$ \\
\hline
\end{tabular}

Santos-Soares and Oliveira-Filho: Thrombosis of the Vein of Galen: Pitfalls, Metamorphosis, and Paroxysmal Sympathetic Hyperactivity

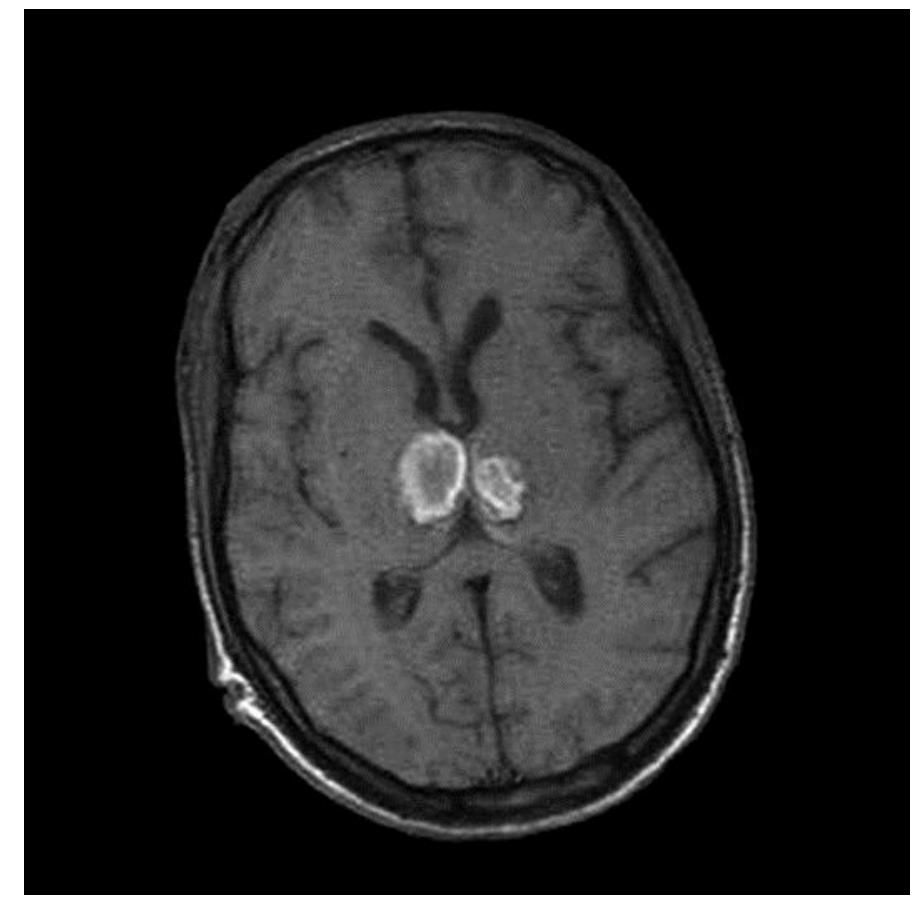

Fig. 1. Axial T1-weighted MR image 5 days after CVT revealing infarct and perilesional edema on both paramedian thalamic regions.

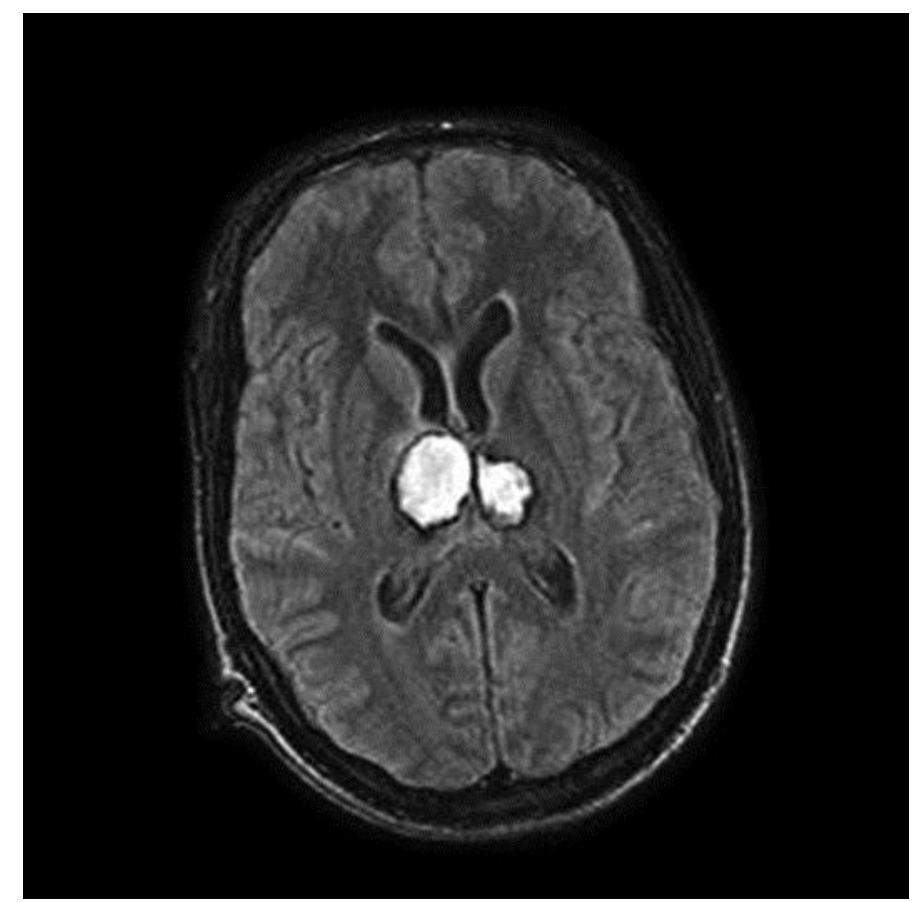

Fig. 2. Fluid-attenuated inversion recovery (FLAIR) MR image on day 5 showing bilateral paramedian thalamic infarcts. 


\section{Case Reports in Neurology}

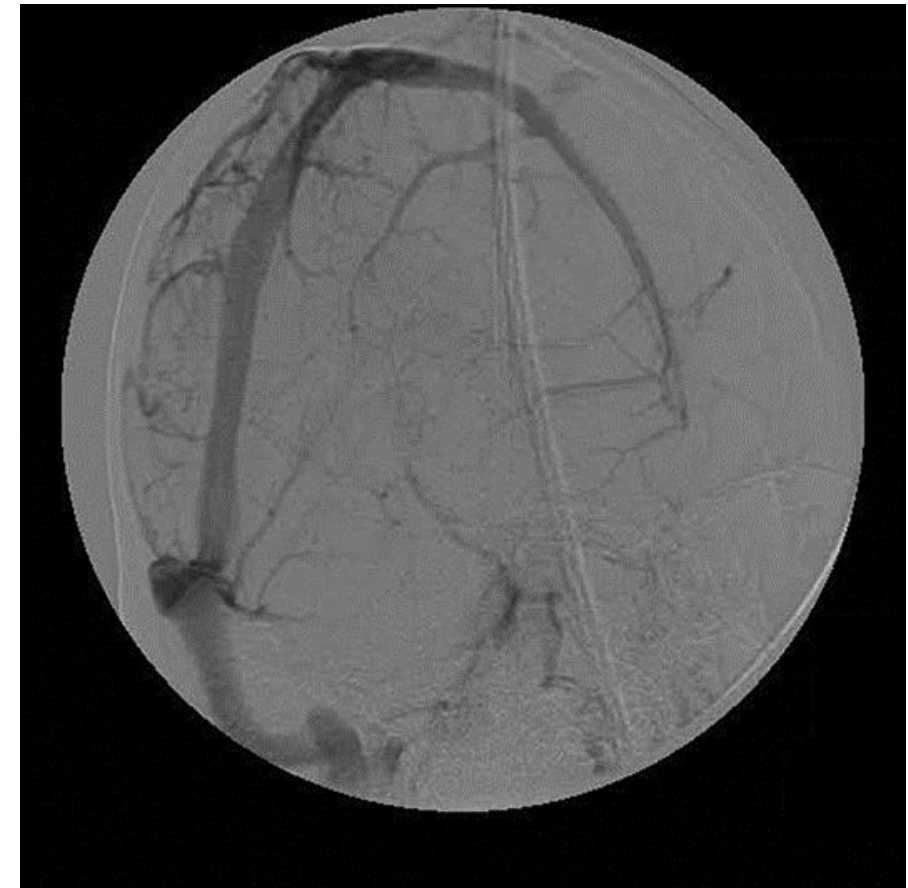

Fig. 3. Angiography, posterior view, showing the absence of flow in the deeper venous structures.

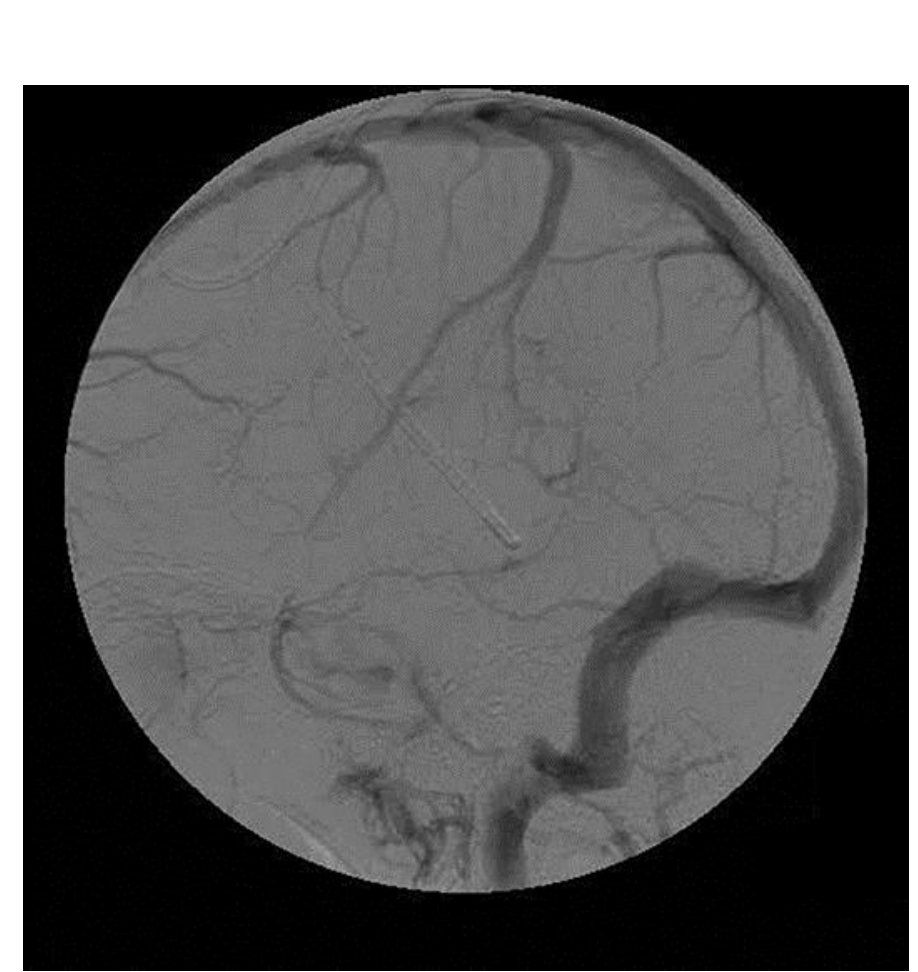

Fig. 4. Angiography, sagittal view, showing the absence of flow in the great vein of Galen.

Santos-Soares and Oliveira-Filho: Thrombosis of the Vein of Galen: Pitfalls, Metamorphosis, and Paroxysmal Sympathetic Hyperactivity

\section{kanger}

